\title{
EFFICIENCY OF TEMPOROMANDIBULAR JOINT ARTHROCENTESIS WITH OZONATED WATER IN MANAGEMENT OF ANTERIOR DISC DISPLACEMENT WITHOUT REDUCTION: A RANDOMIZED CLINICAL TRIAL
}

\author{
Alshaimaa A. Shabaan* and Dina Sabry**
}

\begin{abstract}
Objective: The aim of the study was to evaluate the efficiency of temporomandibular joint arthrocentesis with ozonated water versus ringer lactate in treatment of anterior disc displacement without reduction (closed lock) and to evaluate the effect of both procedures on the level of interleukin-6 (IL-6) in the joint space.

Patients and methods: Forty patients with bilateral anterior disc displacement without reduction were included in the study. Patients were randomly allocated into 2 groups. Group I performed arthrocentesis using ozonated water while group II underwent the same procedure using sodium ringer lactate. Clinical evaluation of the patients was done preoperative, immediately ostoperative, at 1 week and 1,3 and 6 months postoperatively. The pain was assessed using visual analog scales. Maximal mouth opening (MMO) was recorded at each follow-up visit. Synovial fluid sample was collected to detect the level of IL-6, preoperative, immediately postoperative and at six months postoperative
\end{abstract}

Results: Both groups showed improvement in clinical parameters. Concerning maximal mouth opening, there was no statistically significant difference between the two groups pre-operatively, after 1 week as well as after 1 month. After 3 months and 6 months, Group I showed statistically significant higher mean MMO than Group II. the pain score assessment showed no statistical significant difference between the two groups pre-operatively. Through all other periods, Group I showed statistically significantly lower mean VAS scores than Group II. The interleukin-6 levels showed no statistically significant difference between the two groups pre-operatively. Immediately post-operative as well as after 6 months, Group I showed statistically significantly lower mean IL-6 level than Group II.

Conclusion: Arthrocentesis using ozonated water proved to have superior results in treatment of TMJ anterior disc displacement without reduction. Interleukin-6 level in the TMJ synovial fluid has direct correlation with the dysfunction symptoms.

KEY WORDS: Disc displacement without reduction, Ozonated water, Arthrocentesis, Interleukin-6

* Lecturer of Oral \& Maxillofacial Surgery, Faculty of Dentistry, Fayoum University, Egypt.

** Prof. Medical Biochemistry and Molecular Biology, Faculty of Medicine Cairo University. 


\section{INTRODUCTION}

The temporomandibular joint Disorders (TMD) is one of the therapeutic challenge for oral and maxillofacial surgeons. Temporomandibular joint (TMJ) anterior disc displacement without reduction (DDwoR) is a condition where the non-reducible anteriorly displaced disc acts as an obstacle to the gliding of the condyle and affecting the mouth opening, a condition usually referred to as closed lock. Several treatment modalities were proposed for management of such a condition ranging from conservative to surgical means of treatment ${ }^{(1,2)}$.

One of the most prevailing treatment modalities of TMJ closed lock is arthrocentesis. It was first described by Nitzan et al ${ }^{(3)}$ in the early nineties as the simplest form of surgery in the TMJ. The aim of such treatment is removing inflammatory mediators, releasing the articular disc and disrupting the adhesions between the surface of the disc and the articular fossa by hydraulic pressure of the lavage solution ${ }^{(4)}$. Several solutions were used in arthrocentesis like Ringer's lactate, saline or ozonated water ${ }^{(5,6)}$.

In the past decade, the ozone therapy had been widely used in dentistry. Ozone was proved to possess anti- inflammatory and analgesic effects. The anti-inflammatory capacity is due to its ability to oxidize the double bond compounds such as the arachidonic acid and prostaglandins. Moreover, Ozone regulates metabolic reactions in tissues at the place of inflammation and resolves PH. On the other hand, the analgesic effect of ozone is due to its ability of oxidation of the oligopeptides that act on the nerve endings in the damaged tissue and determine the severity of pain response ${ }^{(7)}$. In a study on pain assessment after removal of impacted molars Ozone proved to minimize pain after such surgeries ${ }^{(8)}$. Moreover, Ozone was proved to enhance the host defense mechanism in a study carried out by Huth, et al ${ }^{(9)}$.
Ozone has been used in TMJ lavage as a gas ${ }^{(10)}$ or as ozonated water ${ }^{(11)}$ and it proved efficient both ways to resolve TMJ dysfunction symptoms. On the other hand, a major drawback is associated with Ozone therapy specially the gas form which is ozone toxicity reported during the last years ${ }^{(12)}$.

Interleukin-6 (IL-6) is a multifunctional cytokine that had a major role in host defense and can be produced by many cell types like monocytes, macrophages, T cells and fibroblasts. The Il-6 enhances T- lymphocyte proliferation, B- lymphocyte differentiation and complement cascade activation ${ }^{(13,14)}$.

Several studies focused on the pathogenesis of closed lock and emphasized the role of biochemical changes within the joint ${ }^{(15)}$ and the biochemistry of the synovial fluid in various stages of the TMJ disorders ${ }^{(16)}$. The role of inflammation has been proposed as an underlying mechanism of Pain and dysfunction of TMJ due to the presence of cellular and biochemical signs of inflammation in painful and tender joints ${ }^{(17)}$.

The aim of the present study was to assess the efficacy of Ozone application in arthrocentesis clinically and effect of ozone on the concentration of IL-6 in the synovial fluid pre-and post-procedure.

\section{PATIENTS AND METHODS}

\section{Participants:}

Forty healthy patients complaining from bilateral pain and tenderness over the joint area with limited mouth opening and jaw function participated in this study. Their age ranged from 22 to 45 years. The participants were recruited from Outpatient clinics of Oral and Maxillofacial Surgery Department, Faculty of Dentistry, Fayoum University. Patients were diagnosed as anterior disc displacement without reduction. Diagnosis was based both on clinical and radiographic examination (Fig 1). 


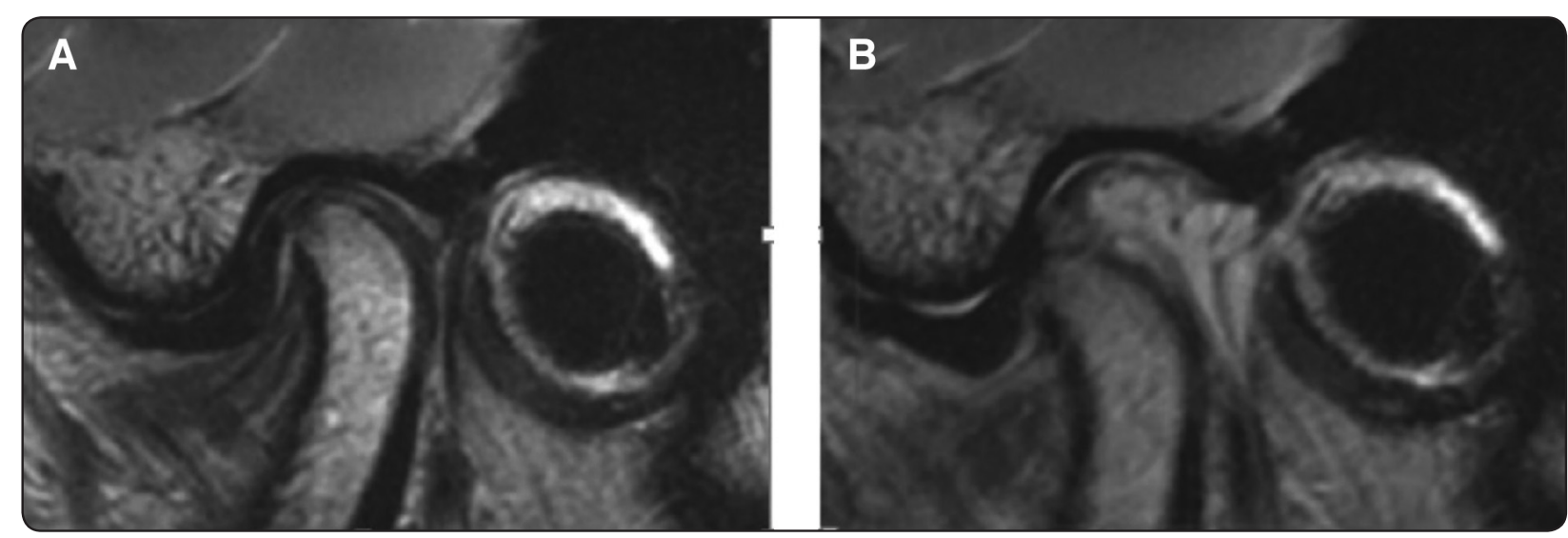

Fig. (1) A ) Anterior displacement of the articular meniscus in relation to the mandibular condyle in closed-mouth position, B) The displaced disc doesn't reduce on mouth opening

Patient selection was based on certain inclusion and exclusion criteria. Exclusion criteria included patients with degenerative joint disease or any systemic inflammatory joint disease, patients with condylar pathology (hypoplasia, hyperplasia or tumor), patients with normal disc positions as seen by the MRI and the limitation is due to another reason, patients who underwent previous TMJ arthrocentesis or any other surgical intervention.

Completed medical and dental history was taken for all patient and subjected to clinical examination including pain, tenderness and maximal mouth opening measurement. All patients performed Magnetic resonance imaging (MRI) for the joint in open and closed mouth position to confirm the position of the disc in front of the condyle in both positions.

Patients were fully informed about the treatment procedures, follow-up examinations and complications of surgical procedures and ozone treatment. Informed consent was obtained from each patient prior to participation in the study.

\section{Grouping and Randomization}

The study was carried out as randomized controlled trial. Patients were randomly divided into two groups twenty patients each. Group I performed arthrocentesis and lavage using ozonated water, while group II patients performed the same procedure using ringer lactate solution. Synovial fluid samples were obtained from each patient in both groups at three stages, once before beginning of the arthrocentesis procedure, the second time after infusion of $300 \mathrm{ml}$ of irritant into the superior compartment of the joint space, and the third sample was collected at six months postoperatively.

All Patients were subjected to a standardized surgical protocol by the same surgeon and another operator carried out the postoperative measurements.

\section{Preparation of Ozonated water}

Ozonated water was prepared using $200 \mathrm{ml}$ of distilled water (distilled water for injection produced by EIPICO, Egypt). It was bubbled with $70 \mu \mathrm{g} / \mathrm{ml}$ Ozone for 30 minutes at room temperature. A medical ozone /oxygen gas mixture produced by ozone generator (Humazon ${ }^{\circledR P R O M E D I C,}$ HUMARES GmbH, Bruchsal Germany). The Ozone generator was fed with medical pure oxygen from a medical oxygen tank.

\section{Surgical procedures}

All patients performed arthrocentesis under local anesthesia, the operative site was disinfected using Betadine solution and the area was isolated with sterile drapes. Auriculotemporal nerve block was performed. The point of needle insertion was determined by drawing the canthal tragus line and a 


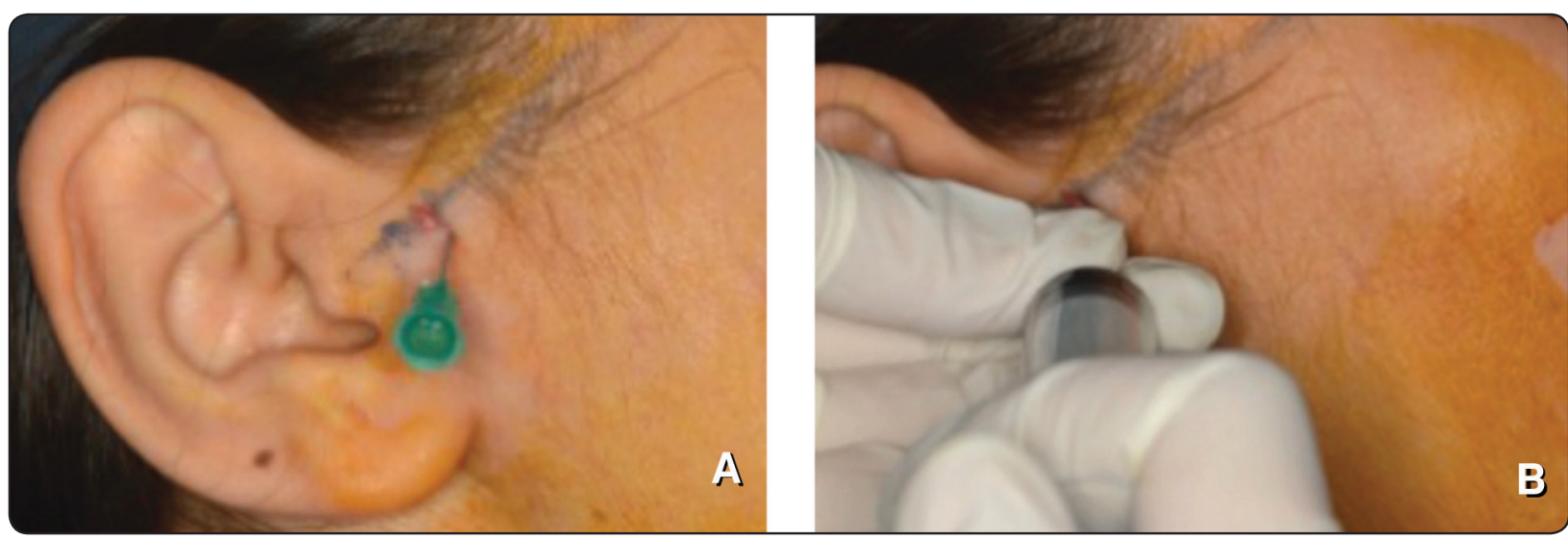

Fig. (2) a) Needle inserted into the superior joint space b) Withdrawal of synovial fluid aspirate before the arthrocentesis

point $10 \mathrm{~mm}$ in front of the tragus and $2 \mathrm{~mm}$ below the canthal tragal line was marked. Another point 2 $\mathrm{mm}$ anterior to the first point is marked for insertion of the second needle which will serve as the outlet.

A needle is inserted into the superior joint space; the joint space is flushed with $2 \mathrm{cc}$ of normal saline. To allow mixing of the solution with the synovial fluid the solution was aspirated and reinjected several times (3 times), and finally the mixture was collected in sterile tubes.

After the synovial fluid sample collection, a second 20-gauge needle was introduced into the joint space through a point $2 \mathrm{~mm}$ anterior to the former needle to establish regular flow during the maneuver. The joint was irrigated using $300 \mathrm{ml}$ of ozonated water in group I or $300 \mathrm{ml}$ of ringer lactate solution in Group II. The outflow needle was periodically occluded to create hydraulic pressure within the joint space. During the maneuver patient was asked to open and close mouth and move it sideways (Fig 3).

The second sample of synovial fluid was collected after the joint lavage using $300 \mathrm{ml}$ of ozonated water was complete. Two $\mathrm{ml}$ of the last fluid emerging from the needle is collected. All the collected samples were immediately centrifuged at 3,000 rpm for 20 minutes to remove cells before storing then the supernatant at $-70{ }^{\circ} \mathrm{C}$ until assay.

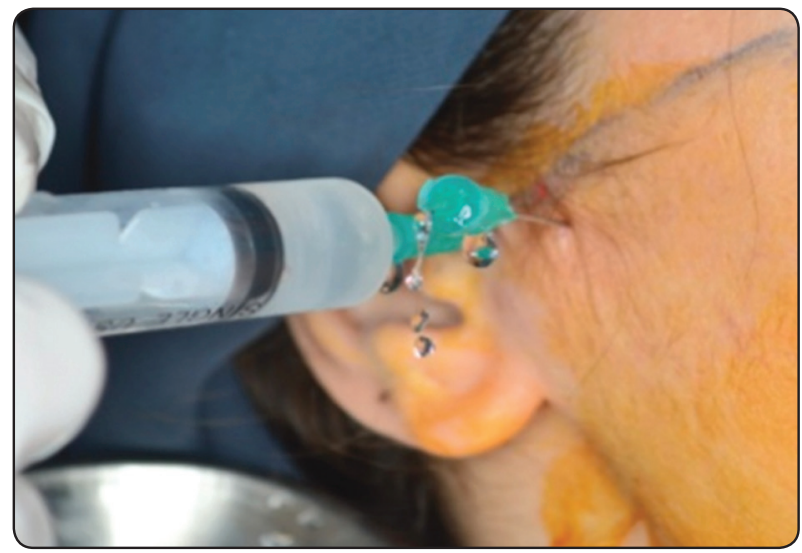

Fig. 3: Arthrocentesis, regular in and out flow of the irrigant in the superior joint space

All patients are given postoperative instructions. The physiotherapy was started immediately postoperatively to promote and maintain an improved range of mandibular movement. A soft diet is recommended for the first few days. Postoperative antibiotic of $875 \mathrm{mg}$ Amoxicillin and $125 \mathrm{mg}$ Clavulanic acid (Augmentin $1 \mathrm{gm}$, Smithline Beecham Pharmaceutical Co., Bentford, England) twice a day for five days post-operatively and non-steroidal anti- inflammatory drug in the form of diclofenac potassium $50 \mathrm{mg}$ (Cataflam 50mg tablets, Novartis Pharma AG, Basle, Switzerland) three times daily were prescribed to the patients. 


\section{Postoperative Follow-up:}

All the patients were evaluated on the $1^{\text {st }}$ week, $4^{\text {th }}$ week, $3^{\text {rd }}$ month and $6^{\text {th }}$ month postoperatively for pain and maximum mouth opening (MMO). Also Synovial fluid sample was collected to detect the level of IL-6, preoperative, immediately postoperative and at six months postoperative.

Pain was assessed using a visual analogue scale (VAS) of 10 units in combination with a graphic rating scale. On the VAS, the left most end represented the absence of pain (score 0) and the right most end indicated the most severe pain (score 10). Preoperative and postoperative mouth opening was measured as the maximal distance between the cutting edge of the maxillary and mandibular central incisors using a caliper.

\section{Statistical analysis}

Numerical data were explored for normality by checking the distribution of data, calculating the mean and median values as well as using the tests of normality (Kolmogorov-Smirnov and ShapiroWilk tests). All data showed parametric (normal) distribution except for pain (VAS scores) which were treated as non-parametric data; so Repeated measures ANOVA test followed by Bonferroni's post-hoc test was used to compare between the two groups as well as to study the changes by time within each group. Student's t-test was used to compare between percentage changes in different variables in the two groups. For VAS scores, MannWhitney U test was used to compare between the two groups. Friedman's test was used to study the changes by time within each group. Wilcoxon signed-rank test with Bonferroni's adjustment was used for pair-wise comparisons between the time periods when Friedman's test is significant. Spearman's correlation coefficient was used to determine significant correlations between IL-6, MMO and pain scores. The significance level was set at $\mathrm{P} \leq 0.05$. Statistical analysis was performed with IBM $®$ SPSS $®$ Statistics Version 20.

\section{RESULTS}

Fourty patients were included in the study. The age of group I ranged from 22- 45 years with a mean of 28.7 years, while that of group II ranged from 20-45 years with a mean of 30 years. Regarding gender distribution, group I was 14 females and six males, while that of group II was 12 females and eight males.

All surgical maneuvers were uneventful, none of the patients suffered from any unusual complications. The results of the collected clinical data were as follow:

\section{Maximal Mouth Opening}

There was no statistically significant difference between the two groups pre-operatively, after 1 week as well as after 1 month. After 3 months, 6 months as well as 12 months, Group I showed statistically significantly higher mean MMO than Group II. In Group I, there was a statistically significant increase in mean MMO after 1 week, from 1 week to 1 month as well as from 1 month to 3 months. From 3 months to 6 months as well as from 6 months to 12 months, there was no statistically significant change in mean MMO. While in Group II, there was a statistically significant increase in mean MMO after 1 week, from 1 week to 1 month as well as from 1 month to 3 months. From 3 months to 6 months, there was no statistically significant change in mean MMO. From 6 months to 12 months, there was a statistically significant decrease in mean MMO. Comparison between \% increases in MMO revealed that there was no statistically significant difference between the two groups through all periods. (Table $1 \& 2$ )

\section{Pain (VAS scores)}

There was no statistically significant difference between the two groups pre-operatively. Through all other periods, Group I showed statistically significantly lower mean VAS scores than Group II. In Group I, there was a statistically significant decrease in mean VAS scores after 1 week, from 
1 week to 1 month as well as from 1 month to 3 months. From 3 months to 6 months as well as from 6 months to 12 months, there was no statistically significant change in mean VAS score (pain scores were zero). While in Group II, there was no statistically significant change in mean VAS scores after 1 week. From 1 week to 1 month as well as from 1 month to 3 months, there was a statistically significant decrease in mean VAS scores. From 3 months to 6 months as well as from 6 months to 12 months, there was no statistically significant change in mean VAS score.

Comparison between \% decreases in VAS scores revealed that Group I showed statistically significantly higher mean \% decrease in VAS scores than Group II through all periods. (Table $1 \& 2$ )

\section{Interleukin-6 (Pg/ml)}

There was no statistically significant difference between the two groups pre-operatively.Immediately post-operatively as well as after 6 months, Group I showed statistically significantly lower mean IL-6 level than Group II. In Group I as well as Group II, there was a statistically significant decrease in mean IL-6 levels immediately post-operatively. From immediate post-operative period to 6 months, there was no statistically significant change in mean IL-6 levels. Comparison between \% decreases in IL-6 levels revealed that Group I showed statistically significantly higher mean $\%$ decrease in IL-6 levels than Group II through all periods. (Table $1 \& 2$ )

TABLE (1) Mean, standard deviation (SD) values and results of comparison between maximal mouth opening (MMO), VAS scores and IL-6 in the two groups as well as the changes after treatment in each group

\begin{tabular}{|c|c|c|c|c|c|}
\hline & \multicolumn{2}{|c|}{ Group I } & \multicolumn{2}{|c|}{ Group II } & \multirow{2}{*}{$\begin{array}{c}P \text {-value } \\
\text { (Between groups) }\end{array}$} \\
\hline & Mean & $S D$ & Mean & $S D$ & \\
\hline MMO (mm) & & & & & \\
\hline Pre-operative & $18.18 \mathrm{~d}$ & 1.63 & $17.98 \mathrm{e}$ & 1.70 & 0.700 \\
\hline 1 week & $23.23 \mathrm{c}$ & 1.71 & $23.26 \mathrm{~d}$ & 2.13 & 0.961 \\
\hline 1 month & $36.66 \mathrm{~b}$ & 1.13 & $36.65 \mathrm{c}$ & 2.30 & 0.993 \\
\hline 3 months & $40.74 \mathrm{a}$ & 0.75 & $39.65 \mathrm{a}$ & 0.88 & $<0.001 *$ \\
\hline 6 months & $41.02 \mathrm{a}$ & 0.80 & $39.73 \mathrm{a}$ & 0.93 & $<0.001 *$ \\
\hline 12 months & $40.96 \mathrm{a}$ & 0.92 & $37.95 \mathrm{~b}$ & 3.26 & $<0.001 *$ \\
\hline$P$-value (within group) & \multicolumn{2}{|c|}{$<0.001 *$} & \multicolumn{2}{|c|}{$<0.001 *$} & \\
\hline \multicolumn{6}{|l|}{ Pain (VAS scores) } \\
\hline Pre-operative & $9.65 \mathrm{a}$ & 0.49 & $9.65 \mathrm{a}$ & 0.49 & 1.000 \\
\hline 1 week & $1.10 \mathrm{~b}$ & 1.07 & $8.30 \mathrm{a}$ & 1.03 & $<0.001 *$ \\
\hline 1 month & $0.15 \mathrm{c}$ & 0.37 & $5.80 \mathrm{~b}$ & 1.82 & $<0.001 *$ \\
\hline 3 months & $0.00 \mathrm{c}$ & 0.00 & $1.30 \mathrm{c}$ & 1.34 & $<0.001 *$ \\
\hline 6 months & $0.00 \mathrm{c}$ & 0.00 & $0.50 \mathrm{c}$ & 1.05 & $0.019 *$ \\
\hline 12 months & $0.00 \mathrm{c}$ & 0.00 & $1.56 \mathrm{c}$ & 3.19 & $0.038 *$ \\
\hline$P$-value (within group) & \multicolumn{2}{|c|}{$<0.001 *$} & \multicolumn{2}{|c|}{$<0.001 *$} & \\
\hline IL-6 (pg/ml) & $10.18 \mathrm{a}$ & 2.25 & $10.18 \mathrm{a}$ & 2.25 & 1.000 \\
\hline Pre-operative & $1.29 \mathrm{~b}$ & 0.61 & $3.39 \mathrm{~b}$ & 1.29 & $<0.001 *$ \\
\hline $\begin{array}{l}\text { Immediate post-operative } \\
6 \text { months }\end{array}$ & $1.63 \mathrm{~b}$ & 0.57 & $4.69 \mathrm{~b}$ & 1.54 & $<0.001 *$ \\
\hline$P$-value (within group) & \multicolumn{2}{|c|}{$<0.001 *$} & \multicolumn{2}{|c|}{$<0.001 *$} & \\
\hline
\end{tabular}


Correlation between IL-6 and clinical parameters

Pre-operatively, there was no statistically significant correlation between IL-6, MMO and pain VAS scores. After 6 months, there was a statistically significant inverse (negative) correlation between
IL-6 and MMO i.e. a decrease in IL-6 level is associated with an increase in MMO and vice versa. (Table $1 \& 2$ ) There was a statistically significant direct (positive) correlation between IL-6 and pain scores i.e. a decrease in IL-6 level is associated with a decrease in pain scores and vice versa. (fig4, 5)

TABLE (2) Mean \%, standard deviation (SD) values and results of comparison between $\%$ changes in different parameters

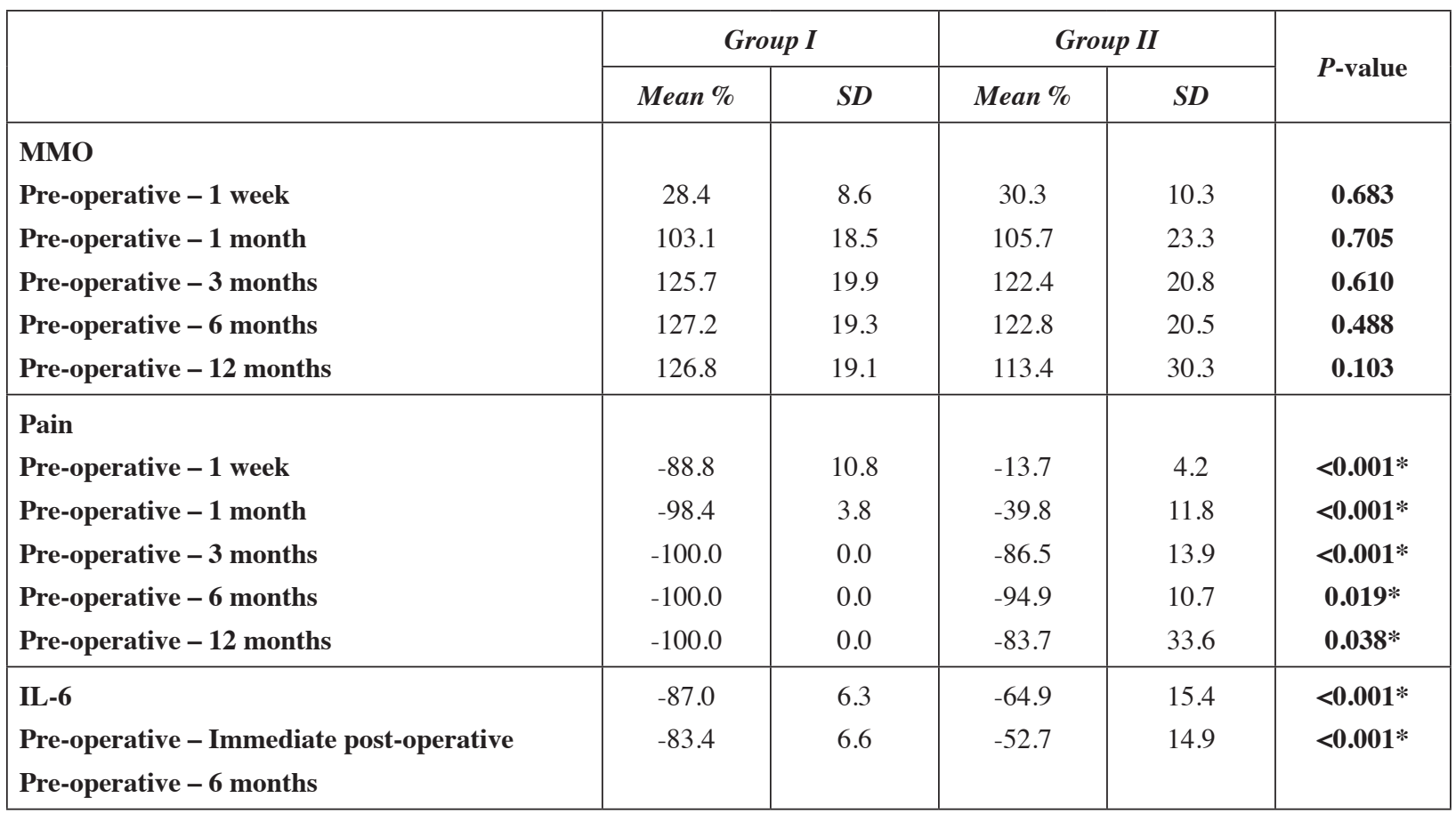

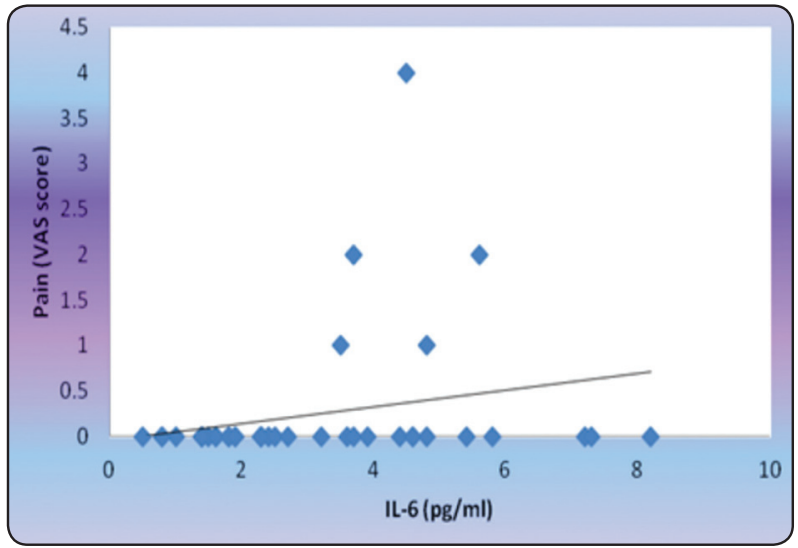

Fig. (4) Scatter diagram representing direct correlation between IL-6 and pain scores after 6 months.

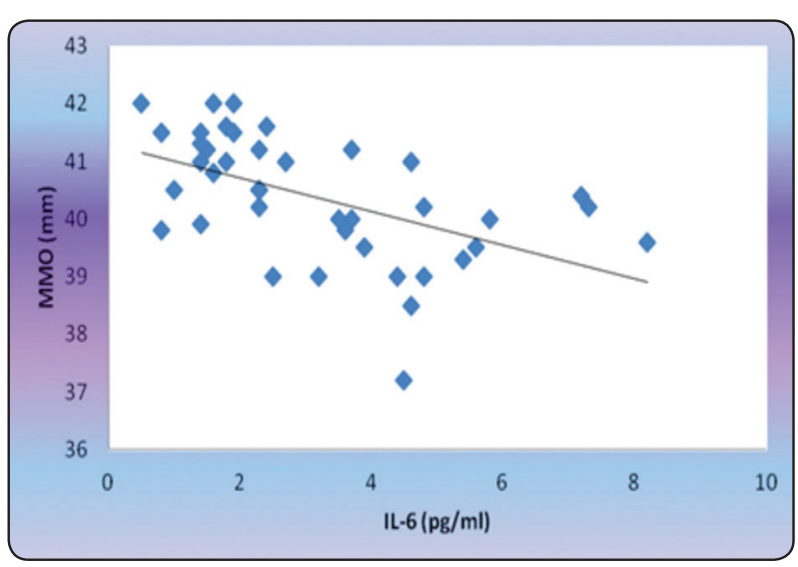

Fig. (5) Scatter diagram representing inverse correlation between IL-6 and MMO after 6 months. 


\section{DISCUSSION}

The present study was conducted on 40 patients suffering from bilateral disc displacement without reduction. The pain scores and maximal mouth opening was evaluated as clinical criteria for evaluating arthrocentesis using ozonated water versus ringer lactate solution in cases of TMJ closed lock. The results in both clinical criteria were in favor with the ozonated water group. The results obtained in this study agrees with that of Daif (10) who conducted a study on the efficacy of Ozone gas in management of TMJ internal derangement in comparison with non-steroidal anti-inflammatories and the results were in favor of the ozone as it subsided the clinical signs and symptoms completely in $87 \%$ of the test group. In another study by Hammuda, et al ${ }^{(11)}$ in 2013, they proved the superior results of arthrocentesis using ozonated water in resolving clinical symptoms of TMJ internal derangement.

In 2006 Benvenuti ${ }^{(18)}$ in a study on large joints like Shoulder, knee and hip, the joints were injected with intra and periarticular micro doses of oxygen ozone gas mixture. All patients experienced relief of pain together with good functional recovery. Moreover Mishra ${ }^{(19)}$, et al in another study on knee osteoarthritis, the results obtained agree with current study as patients receiving Ozone faced success rate of $80 \%$ in three months.

Regarding the IL-6 level, our results showed that elevation of IL-6 level is associated with TMJ dysfunction symptoms (pain intensity and decrease in MMO). This finding agrees with concepts suggesting that a change in position of the disc is not the only factor in dysfunction and pain in TMJ but there are other contributing factors such as the alteration in joint pressure and the presence of inflammatory mediators. This explains increased preoperative levels of IL-6 in both groups and their decrease in the immediate postoperative sample due to washing away of the inflammatory mediators in the joint.
Our results are coherent with those found by Sandler ${ }^{(21)}$, et al in a study in late nineties to evaluate the presence of the inflammatory cytokines interleukin-1 beta (IL-1 beta), interleukin-6 (IL-6), and tumor necrosis factor-alpha (TNF-alpha) within the superior joint space in patients with internal derangements and to compare these values with the pathologic findings seen arthroscopically. The results obtained proved that the presence of IL- 6 correlated with the degree of acute synovitis and internal derangement. Other studies obtained the same results and were able to correlate the presence of IL- 6 to the degree of internal derangement of the joint $^{(22,23)}$.

Also our results agrees with those of Kaneyama et al (24) in 2005, they proved the increased levels of various cytokines including IL-6 in the synovial fluid of patients with TMJ disorders and but failed to find any correlation between cytokines levels and the presence of pain. However the present study results correlated the high pain intensity with elevated levels of IL-6.

In a more recent study by Kristensen, et $\mathrm{al}^{(25)}$ investigating the presence of inflammatory cytokines in healthy joints. The study proved the presence of some types of cytokines in healthy joints, however it proved that IL-6 is hardly found in any healthy joint.

Regarding our study results the levels of interleukin-6 was decreased after arthrocentesis in both groups. However, group I showed more decrease in IL-6 levels both immediately postoperative and at six months postoperative. This may be due to the ozone power of depressing cytokine production. the results obtained here are in coherence with those of Bocci, et al (26) who proved in a study in 1998 that constant (up to $30 \mathrm{sec}$ ) exposure to an ozone flux or a high ozone concentration (108 micrograms $/ \mathrm{ml}$ ) markedly decreases reduced glutathione levels and depresses cytokine production in human blood. 


\section{CONCLUSION}

Within the limitations of the current study, it may be concluded that arthrocentesis using ozonated water is an effective method for treatment of TMJ anterior disc displacement without reduction. It provided better results concerning clinical criteria (Pain intensity and MMO), and minimized the level of IL-6 within the joint synovial fluid for six months.

\section{Conflicts of Interests:}

The authors declare that there are no competing interests regarding the publication of this paper.

\section{REFRENCES}

1. Bouchard C, Goulet JP, El-Ouazzani M, Turgeon AF. Temporomandibular Lavage Versus Nonsurgical Treatments for Temporomandibular Disorders: A Systematic Review and Meta-Analysis. J Oral Maxillofac Surg. 2017;75:1352-62.

2. Holmlund AB, Axelsson S, Gynther GW. A comparison of discectomy and arthroscopic lysis and lavage for the treatment of chronic closed lock of the temporomandibular joint: A randomized outcome study. Journal of Oral and Maxillofacial Surgery, 2001; 59: 972-77.

3. Nitzan DW, Dolwick MF, Martinez GA. Temporomandibular joint arthrocentesis: a simplified treatment for severe, limited mouth opening. J Oral Maxillofac Surg, 1991; 49: 1163-67.

4. Dimitroulis G, Dolwick M F, and Martinez A, "Temporomandibular joint arthrocentesis and lavage for the treatment of closed lock: a follow-up study,". British Journal of Oral and Maxillofacial Surgery .1995; 33 : 23-27.

5. Sato S, Oguri S, Yamaguchi K, Kawamura H, Motegi K. Effect of pumping with injection of sodium hyaluronate and the other factors related to outcome in patients with non-reducing disc displacement of the temporomandibular joint. Int J Oral Maxillofac Surg, 2001; 30: 194-198.

6. Doğan M, Ozdemir Doğan D, Düger C, Ozdemir Kol, Akpınar A, Mutaf B, Akar T Effects of high-frequency biooxidative ozone therapy in temporomandibular disorderrelated pain. Med Princ Prac. 2014; 23:507-510.

7. Akdeniz SS, Beyler E, Korkmaz Y, Yurtcu E, Ates U, Araz K, Sahin FI, Torun OYThe effects of ozone application on genotoxic damage and wound healing in bisphosphonateapplied human gingival fibroblast cells. Clin Oral Investig. 2017 Jul 11.

8. Kazancioglu HO, Kurklu E, Ezirganli S. Effects of ozone therapy on pain, swelling, and trismus following third molar surgery. Int J Oral and Maxillofac Surg, 2014; 43:644-648.

9. Huth KC, Saugel B, Jakob FM, Cappello C, Quirling M, Paschos E, Ern K, Hickel R, Brand K. Effect of aqueous ozone on the NF kappa B system. J Dent Res. 2007; 86: 451-456.

10. Daif ET Role of intra-articular ozone gas injection in the management of internal derangement of the temporomandibular joint. Oral Surg Oral Med Oral Pathol Oral Radiol. 2012; 113: e10-4.

11. Hammuda A, Hamed MS, Elsharrawy EA, Elsholkamy MA, Iskander A. Use of Ozone in Temporomandibular joint arthrocentesis. Clinical study. Journal of American Science .2013; 9: 508-513

12. Bocci V: Ozone as Jenus: This controversial gas can be either toxic or medically useful. Mediators of Inflammation, 2004;13:3-11.

13. Kellesarian SV, Al-Kheraif AA, Vohra F, Ghanem A, Malmstrom H, Romanos GE, Javed F. Cytokine profile in the synovial fluid of patients with temporomandibular joint disorders: A systematic review. Cytokine. 2016; 77:98-106

14. Hirano T. IL-6 and its receptor. Ten Years Later. International Reviews of Immunology, 1998; 16:249-284.

15. Milam SB, Schmitz JP. Molecular biology of temporomandibular joint disorders; proposed mechanisms of disease. .J Oral Maxillofac Surg, 1995; 59:36-45.

16. Nishimura M, Segami N, Kaneyama K, Sato J, Fujimura $\mathrm{K}$. Comparison of cytokine level in synovial fluid between successful and unsuccessful cases in arthrocentesis of the Temporomandibular joint. J Oral Maxillofac Surg, 2004; 62:284-7.

17. Sato J, Segami N, Nishimura M, Demura n, Yoshimura H, Yoshitake Y, et al. Expression of interleukin-6 in synovial tissues in patients with internal derangement of the Temporomandibular joint. Br J Oral and Maxillofac Surg, 2003;41:95-101.

18. Benveuti P. Oxygen-Ozone Treatment of the Knee, Shoulder and Hip A Personal Experience. Rivista Italiana di Ossigeno-Ozonoterapia.2006;5:135-144 
19. Mishra SK, Pramanik R,Das P,Das PP, Palit AK, Roy J, Halder RN.Role of intra- articular Ozone in oste-oarthritis of knee for functional and symptomatic improvement. Indian Journal of physical medicine and rehabilitation, 2011; 22: 65-69.

20. Lobezzo F, Drangsholt M, Peck C, Sato H, Kopp S, Svensson $\mathrm{P}$. Topical review: new insights into the pathology and diagnosis of disorders of the temporomandibular joint. J Orofac Pain 2004; 18:181-91.

21. Sandler NA, Buckley MJ, Cillo JE, Braun TW. Correlation of inflammatory cytokines with arthroscopic findings in patients with tempromandibular joint internal derangements. .J Oral Maxillofac Surg, 1998;56:534-43

22. Murakami K,Shibata T, Kubota E, Maeda H. Intraarticular levels of prostaglandin E2, hyaluronic acid, and chondroitin-4and-6 sulfates in the Temporomandibular joint synovial fluid of patients with internal derangement. J Oral Maxillofac Surg, 1998;56:199-203
23. Keun J.L, Sook Y.C, and Song S.: Relationship of Synovial Tumor Necrosis Factor-alpha and Interleukin 6 to Temporomandibular Disorder. J Oral Maxillofac Surg, 2010; 68:1064-1068

24. Kaneyama K, Segami N, Sun W, Sato J, Fujimura K. Levels of soluble cytokine factors in temporomandibular joint effusions seen on magnetic resonance images. Oral surg Oral Med Oral Pathol Oral Radiol Endod, 2005; 99: 411-8.

25. Kristensen KD, Alstergren P, Stoustrup P, Küseler A, Herlin T, Pedersen TK Cytokines in healthy temporomandibular joint synovial fluid. Journal of oral rehabilitation 2014; 41 : 250-6.

26. Bocci V, Luzzi E, Corradeschi F, Paulesu L, Rossi R, Cardaioli E, Di Simplicio P .Studies on the biological effects of ozone: 4. Cytokine production and glutathione levels in human erythrocytes. Journal of Biological Mediators and Homeostatic Agents, 1993; 7:133-138. 